\title{
Disorders of carbohydrate metabolism and their relationship with the prevalence of cancer in patients with acromegaly - authors' own observations
}

\author{
JOANNA ELŻBIETA MALICKA, A, B, D-F, MARIA KUROWSKA, B, D, E, MARTA DUDZIŃSKA 2, c, D, E, \\ AGATA SMOLEN'³, C, ANNA OSZYWA-CHABROS1, D, E, JERZY S. TARACH'1, B, D, E \\ ${ }^{1}$ Department of Endocrinology, Medical University of Lublin \\ ${ }^{2}$ Chair of Internal Medicine and Department of Internal Medicine in Nursing, Medical University of Lublin \\ ${ }^{3}$ Chair and Department of Epidemiology and Clinical Research Methodology, Medical University of Lublin
}

A - Study Design, B - Data Collection, C - Statistical Analysis, D - Data Interpretation, E - Manuscript Preparation, $\mathbf{F}$ - Literature Search, $\mathbf{G}$ - Funds Collection

Summary Background. Acromegaly is a rare chronic disease with an excessive secretion of growth hormone, which leads to characteristic changes in appearance, organ and metabolic complications and neoplasms, which are a significant cause of shortened survival time. One of the most common consequences of acromegaly is disturbed carbohydrate metabolism.

Objectives. The aim of this study was to assess the prevalence of disorders of carbohydrate tolerance and their relationship with the prevalence of malignant tumours in subjects with acromegaly.

Material and methods. The study group comprised 69 patients with confirmed acromegaly (26 M, 43 F), aged 26-83 (mean $58.9 \pm 11.0$ ). Medical histories and the results of laboratory tests - plasma fasting glucose and oral glucose tolerance test, as well as the results of imaging and histopathological examinations performed in cases of suspected cancer lesions were analyzed.

Results. Disorders of carbohydrate tolerance were confirmed in a total of 46 patients (66.7\%). 23 patients (33.3\%) had normal glucose tolerance. Diabetes was diagnosed in 22 patients (31.9\%), while prediabetes was diagnosed in $24(34.8 \%)$ patients. In the analyzed group there were 6 cases of cancers, including 5 patients with concomitant diabetes, which represented a value significantly higher $(p=0.01)$ compared to patients without diabetes. The sixth case of cancer was detected in a woman with IGT. In patients with normal glucose tolerance there was no case of cancer.

Conclusions. Among patients with acromegaly, disorders of carbohydrate tolerance occur in more than half of the cases, which confirms the need for active screening in this group of patients, in which a significant role is played by General Practitioners. General Practitioners should also consider the possibility of acromegaly in the differential diagnosis of glucose tolerance disorders detected in their patients. All patients with acromegaly, especially with concomitant diabetes or prediabetes, should be screened for cancers.

Key words: acromegaly, diabetes, prediabetes, malignancy.

Fam Med Prim Care Rev 2016; 18(3): 291-293

\section{Background}

Somatotropic pituitary adenomas excessively secreting growth hormone $(\mathrm{GH})$, causing acromegaly occur with a frequency of 50-70 cases/million inhabitants. The consequence of the disease is the excessive production of growth factors (mainly insulin-like growth factor-1, IGF-1), which leads to characteristic changes in the appearance of patients, organ and metabolic complications and neoplasms [1, 2]. Slow changes in appearance and the rich symptomatology of acromegaly are a frequent cause of diagnostic errors in the practice of General Practitioners and delay diagnosis of the disease by an average of 5-10 years. The most frequent reasons for presenting patients to General Practitioners are: nodular goiter, hypertension, osteoarthritis, hyperglycemia, and sleep apnoea syndrome $[1,3]$.

One of the most common complications of acromegaly is disturbed carbohydrate metabolism, and this affects more than half of patients with various degrees of disease severity: hyperinsulinaemia (up to $80 \%$ ), glucose intolerance (up to $40 \%$ ), and diabetes (up to $20 \%$ ) [2].
Diabetes (diabetes mellitus - DM) in the course of acromegaly belongs to a heterogeneous group of secondary diabetes (of known etiology and pathogenesis). Apart from Cushing's syndrome, acromegaly is the most frequent endocrinopathy causing a disorder of this type, which in the early period results mainly from insulin resistance, and in the later one is also caused by insulin deficiency [4]. Excessive secretion of $\mathrm{GH}$ and IGF-1 in acromegaly has an opposite effect on carbohydrate metabolism. GH reduces the uptake and oxidation of glucose in muscle tissue, increases hepatic gluconeogenesis, and causes insulin resistance by the activation of lipolysis and an increase in the concentration of free fatty acids [5-7]. It is a hormone which exerts an antagonistic hepatic and peripheral effect in comparison to insulin, which is physiologically important in the prevention of hypoglycaemia, and is also responsible for "stress" diabetes and probably for the "dawn phenomenon" (increase in the demand for insulin in the morning) [6]. In comparison to GH, IGF-1 exerts effects similar to insulin (especially in the muscle tissue), decreases blood glucose level, and has been used experimentally in the treatment of type 1 and 2 diabetes $[7,8]$. 
$\mathrm{GH}$ and IGF-1 also demonstrate proliferative and antiapoptotic activity, and long-term exposure to their excess increases the risk of cancer, representing the third cause of death in this group of patients $[9,10]$.

\section{Objectives}

The aim of this study was to assess the prevalence of disorders of carbohydrate tolerance and their relationship with the prevalence of malignant tumours in subjects with acromegaly.

\section{Material and methods}

The study group comprised 69 patients (26 men, or $37.7 \%$ and 43 women, or $62.3 \%$ ), aged from 26 to 83 (58.9 \pm 11.0 ), remaining under the care of the Department of Endocrinology and Endocrinology Hospital Outpatient Clinic in Lublin in the years 2000-2015. Active acromegaly was confirmed based on lack of inhibition of $\mathrm{GH}$ secretion in the oral glucose tolerance test with $75 \mathrm{~g}$ of glucose, elevated concentration of IGF-1 and the presence of pituitary adenoma in magnetic resonance (MR) examination. Medical histories and the results of laboratory tests - plasma fasting glucose in venous blood and oral glucose tolerance test with $75 \mathrm{~g}$ of glucose, as well as the results of imaging and histopathological examinations performed in cases of suspected cancer lesions were analyzed.

The obtained results were subjected to statistical analysis using STATISTICA v. 10.0 software (StatSoft, Poland). Values of the analyzed parameters measured in a nominal scale were characterized using count and percentage, while in the ratio scale using mean value and standard deviation. Variables with normal distribution (patients' age) were evaluated using the Shapiro-Wilk test. The Mann-Whitney $U$ test was used for the comparison of two independent groups. To detect the existence of differences or dependencies, the chi-squared test was used; a 5\% error of inference was assumed.

\section{Results}

Disorders of carbohydrate tolerance were confirmed in a total of 46 patients $(66.7 \%), 28$ women $(65.1 \%)$ and 18 men $(69.2 \%) .23$ patients $(33.3 \%)$ had normal glucose tolerance (15 $\mathrm{F}=34.9 \% ; 8 \mathrm{M}=30.8 \%$ ).

Diabetes was diagnosed in 22 subjects $(31.9 \%), 15$ women (or $34.9 \%$ ) and 7 men (or 26.9\%). Prediabetes was diagnosed in 24 patients $(34.8 \%)$, including impaired fasting glucose - IFG in 12 subjects (17.4\%), impaired glucose tolerance - IGT in $8(11.6 \%)$, while in 4 patients $(5.8 \%) \mathrm{im}$ paired fasting glucose coexisted with impaired glucose tolerance. IFG was detected in the same number of women and men ( 6 subjects in each group, or in $13.9 \%$ of $F$ and $23.1 \%$ of M), similarly to concomitant IFG + IGT - 2 subjects in each group ( $4.6 \%$ of $\mathrm{F}$ and $7.7 \%$ of $\mathrm{M})$. IGT was found in 5 women $(11.6 \%)$ and 3 men $(11.5 \%)$.

In the whole group 6 cases of cancer in $8.7 \%$ of patients (5 $\mathrm{F}$ and $1 \mathrm{M}$ ) were found: one case each of the ascending colon, rectum, stomach, endometrium, breast, and thalamic astrocytoma. All of these cancers occurred significantly more often ( $p=0.01)$ in subjects with concomitant diabetes in comparison to the remaining patients ( $22.7 \%$ vs. $2.13 \%)$. No similar relationship between the prevalence of cancers and the presence of prediabetes was found, wherein 1 case of breast cancer in a woman with IGT was diagnosed. In patients with normal glucose tolerance there was no case of cancer.

No statistically significant relationship between the occurrence of impaired carbohydrate metabolism and available demographic data was found. With age the study patients acquired cancers significantly more frequently $(p=0.01)$.

\section{Discussion}

In the analyzed group of patients disorders of carbohydrate tolerance occurred in more than half of the subjects $(66.7 \%)$, with a percentage slightly higher than reported by other authors: Valea et al. - DM - $12 \%$, IFG - 28\%, IGT $-16 \%$ (56\% in total) [7], Alexopoulou et al. - IFG and IGT - 26\%, DM - 28\% (54\% in total) [11]. Diabetes was diagnosed in $31.9 \%$ of subjects, similarly to Wen-Ko et al. (37.2\%) [12] or Zieleniewski and Michalak - (32\%) [13] and in a percentage higher than Valea et al. $-12 \%$ [7]. These differences probably result from different criteria of the diagnosis of disorders of carbohydrate tolerance adapted in different countries, as well as different patient populations (prospective and retrospective studies, different geographic zones, eating habits, BMI, age), but all the studies clearly demonstrate the importance of the problem.

There is much evidence confirming the negative impact of diabetes on the survival time of patients, which especially concerns patients with acromegaly. Wen-Ko et al. demonstrated a shorter survival time of patients with acromegaly and diabetes compared with a subgroup with acromegaly without diabetes, while levels of GH and IGF-1 in patients with diabetes were only slightly higher (to a statistically insignificant extent) [12]. These researchers also confirmed a lower percentage of surgically treated patients in the subgroup with concomitant diabetes [12].

It is widely known that $\mathrm{GH}$ and IFG- 1 are proliferative and anti-apoptotic factors, while hyperinsulinaemia probably plays an additional role, stimulating cell growth and division in concomitant diabetes, as it occurs in type 2 DM $[14,15]$. Therefore, the most serious complications of acromegaly, especially with concomitant diabetes, are cancers, mainly of the gastrointestinal tract, but also of other organs: breast, prostate, brain $[2,9,10,13,16]$. In the group of 106 patients suffering from acromegaly with concomitant diabetes, Wen-Ko et al. demonstrated a higher prevalence of cancers as compared to patients with acromegaly without diabetes $(13.2 \%$ vs. $3.5 \% ; p<0.01)[12]$.

The present results also confirm this tendency. In the analyzed group there were 6 cases of cancers, including 5 patients with concomitant diabetes, which represented a value significantly higher compared to patients without diabetes $(22.7 \%$ vs. $2.13 \% ; p=0.01)$, while the sixth case of cancer was detected in a woman with prediabetes (IGT). In patients with normal glucose tolerance there was no case of cancer.

It was found that a statistically significant relationship between age and the prevalence of cancers is probably a reflection of the general trend (ageing population), but it may also result from a longer time of exposure to the proliferative activity of $\mathrm{GH}$ and IFG-1.

A limitation of the present study is the relatively small group of patients, associated with the rare prevalence of acromegaly in the general population. However, despite this, the present observations, similarly to those of the above-quoted authors $[2,9,10,13,16]$, confirm the need for increased oncologic control of patients with acromegaly, according to Polish recommendations [2], and especially of patients with concomitant disorders of carbohydrate metabolism.

\section{Conclusions}

Because of the very high prevalence of disorders of carbohydrate metabolism in patients with acromegaly, there is a need for active screening for glucose intolerance in this group of patients, in which a significant role is played by 
General Practitioners. General Practitioners should also consider the possibility of acromegaly in the differential diagnosis of glucose tolerance disorders diagnosed in their patients.
As both diabetes and cancers are important factors influencing the increased mortality of patients with acromegaly, they require careful observation, periodic screening examinations for cancers and appropriate treatment.

Source of funding: This work was funded by the authors' resources. Conflict of interest: The authors declare no conflict of interests.

\section{References}

1. Kałużny M, Bolanowski M. Acromegaly - a possible cause of diagnostic errors in family doctor's practice. Fam Med Prim Care Rev 2009; 11(2): 173-178.

2. Bolanowski M, Ruchała M, Zgliczyński W, et al. Acromegaly - a novel view of the patient. Polish propos al of diagnostics and therapeutic procedure in the light of recent reports. Endokrynol Pol 2014; 65(4): 326-331, doi: 10.5603/EP.2014.0045.

3. Bolanowski M, Kałużny M, Jawiarczyk A. Akromegalia - możliwe trudności diagnostyczne w praktyce lekarza rodzinnego. Fam Med Prim Care Rev 2010; 12(2): 317-319.

4. Nomiyama T, Yanase T. Secondary diabetes. Nihon Rinsho 2015; 73(12): 2008-2012 (Abstract).

5. Urbani C, Sardella C, Calevro A, et al. Effects of medical therapies for acromegaly on glucose metabolism. Eur J Endocrinol 2013; 169(1): 99-108, doi: 10.1530/EJE-13-0032.

6. Mřller N, Jřrgensen JO. Effects of growth hormone on glucose, lipid, and protein metabolism in human subjects. Endocr Rev 2009; 30(2): 152-177, doi: 10.1210/er.2008-0027.

7. Valea A, Carsote M, Ghervan C, et al. Glycemic profile in patients with acromegaly treated with somatostatin analogue. J Med Life 2015; 8 Spec. Issue: 82-86.

8. LeRoith D, Yakar S. Mechanisms of disease: metabolic effects of growth hormone and insulin-like growth factor 1 . Nat Clin Pract Endocrinol Metab 2007; 3(3): 302-310.

9. Colao A, Ferone D, Marzullo P, et al. Systemic complications of acromegaly: epidemiology, pathogenesis, and management. Endocr Rev 2004; 25(1): 102-152.

10. Jenkins PJ, Besser M. Clinical perspective: acromegaly and cancer: a problem. J Clin Endocrinol Metab 2001; 86(7): $2935-2941$.

11. Alexopoulou O, Bex M, Kamenicky $P$, et al. Prevalence and risk factors of impaired glucose tolerance and diabetes mellitus at diagnosis of acromegaly: a study in 1488 patients. Pituitary 2014; 17(1): 81-89, doi: 10.1007/s11102-013-0471-7.

12. Wen-Ko C, Szu-Tah C, Feng-Hsuan L, et al. The impact of diabetes mellitus on the survival of patients with acromegaly. Endokrynol Pol 2016; Feb 17, doi: 10.5603/EP.a2016.0031. [Epub ahead of print].

13. Zieleniewski W, Michalak R. Akromegalia - niedoceniony problem zdrowotny w praktyce lekarza rodzinnego. Fam Med Prim Care Rev 2011; 13(2): 273-275.

14. Bensimon L, Yin H, Suissa S, et al. Type 2 diabetes and the risk of mortality among patients with prostate cancer. Cancer Causes Control 2014; 25(3): 329-338, doi: 10.1007/s10552-013-0334-6.

15. Khandwala HM, McCutcheon IE, Flyvbjerg A, et al. The effects of insulin-like growth factors on tumorigenesis and neoplastic growth. Endocr Rev 2000; 21(3): 215-244.

16. Ruchała M, Szczepanek-Parulska E. Rak tarczycy a akromegalia. Thyroid International 2015; 1: 3-11.

Address for correspondence:

Joanna Malicka, MD, PhD

Klinika Endokrynologii SPSK 4

ul. Jaczewskiego 8

20-954 Lublin

Polska

Tel.: +48 81 724-46-68

E-mail jdmaliccy@poczta.onet.pl

Received: 06.03.2016

Revised: 05.04.2016

Accepted: 23.04.2016 